\title{
The relationship between the rs4986791 variant of the TLR4 gene and the severity of bronchial asthma in children
}

\author{
Xiaoqing Chen, ${ }^{1}$ Kai Wang, ${ }^{1}$ Qin Yao, ${ }^{1}$ Lixin Peng, ${ }^{1}$ Lin Wei ${ }^{2}$
}

\begin{abstract}
Background: Toll-like receptor 4 (TLR4) is an important receptor for lipopolysaccharide and lipid A, components of gram-negative bacteria. At present, a variant in TLR4 has been shown to be associated with asthma, but it has not been reported whether variants in TLR4 are associated with bronchial asthma in children.
\end{abstract}

Objective: The objective is to determine the relationship between the rs4986791 (+1196C/T) variants of TLR4 and bronchial asthma in Chinese children.

Methods: DNA extracted from peripheral blood samples was amplified and the Bi-PASA technique was carried out to identify the genotypes in 600 patients.

Results: The result showed no difference between the $1196 \mathrm{C} / \mathrm{T}$ variant of TLR4 and hemoglobin level, proportion of neutrophils and lymphocytes, leukocyte, basophil and eosinophil counts, $\log _{10} \operatorname{IgE}$ and hsCRP in the peripheral blood of bronchial asthmatic patients. However, the eosinophil ratio, FEV1\% and FEV $/$ FVC level of asthma patients with the CT genotype was lower than those of patients with the CC genotype, which were $1.19 \pm 0.10$ and $1.67 \pm 0.18(P$ $=0.01), 81.25 \pm 0.50$ and $84.99 \pm 0.65(P<0.0001), 81.72 \pm 0.568$ and $5.55 \pm 0.78(P<0.0001)$, respectively. The incidence of bronchial asthma in patients with the CT genotype is higher than that in patients with the CC genotype. We analysed the influence of the two genotypes on the current medical history by multiple logistic regression, performing a comparative analysis between the two genotypes and bronchial asthma $(P<0.05)$. Patients with moderately persistent asthma with the CT genotype are more likely to develop severely persistent asthma compared to those with the CC genotype $(P<0.01)$.

Conclusions: This comparative analysis between rs4986791 and bronchial asthma in children indicates that this variant is associated with bronchial asthma risk in Chinese children.

Key words: TLR4, variant, bronchial asthma, children

From:

${ }^{1}$ Huaihua No.1 People's Hospital affiliated to Nanhua University, Huaihua, Hunan, China

${ }^{2}$ College of Basic Medicine, Guizhou University of Traditional Chinese Medicine, Guiyang, China
Corresponding author:

1. Lixin Peng

E-mail: lixinp100@126.com

2. Lin Wei

E-mail: weilin187@gzy.edu.cn

\section{Introduction}

Asthma is a chronic allergic inflammatory disease of the respiratory tract, in which the respiratory response to a variety of specific or non-specific stimuli is abnormally increased. Asthma can occur in people of any age, but most cases begin in childhood. Variant cough, a type of childhood asthma, is often misdiagnosed as other conditions such as bronchitis or a recurrent respiratory tract infection. Chronic variant cough is the main symptom of asthma, and its pathogenesis is the same. In clinical diagnosis, variant cough in children is an early manifestation of childhood asthma. Chronic variant cough and asthma are common diseases in children, consisting of a persistent inflammatory response caused by the body's antagonism of the original or non-antigenic stimulation. Asthma is one of the most common diseases in the world. ${ }^{1}$ The condition is an inflammatory disorder of the airways, which is frequently characterized by excessive $\mathrm{T}$ helper (Th) type 2-biased immune responses. ${ }^{2}$ Although the exact mechanisms of asthma pathogenesis have not been completely 
elucidated, ${ }^{3}$ it is generally accepted that both genetic and environmental factors play important roles in this disease. ${ }^{4}$ Currently, more than 200 genetic variations have been reported to be associated with asthma. ${ }^{5}$

Toll like receptors (TLRs) are important pattern recognition receptors (PRRs), belonging to the transmembrane receptor family, ${ }^{6}$ which play an essential role in activation of the innate and adaptive immune system. ${ }^{7}$ They are mainly expressed on the surface of dendritic cells and macrophages, and are the first barrier for the organism to resist pathogen invasion. TLRs play an important role in the occurrence and development of various kinds of inflammation, signaling through nuclear factor- $\kappa \mathrm{B}(\mathrm{NF} \kappa \mathrm{B})$, mitogen-activated protein (MAP) kinases and interferon regulatory factors 3 (IRF-3) to stimulate production of many inflammatory cytokines and type I interferon. ${ }^{8}$ In turn, these cytokines activate antigen-presenting cells (APCs), influence $\mathrm{T}$ cell polarization and development, ${ }^{2}$ and modulate the function of regulatory T cells. ${ }^{9}$ As a member of the TLR family, TLR4 is the receptor for the lipopolysaccharide and lipid A found in gram negative bacteria. When lipopolysaccharide binds to TLR4, it first causes the recruitment of a series of adaptor proteins, including tumor necrosis factor receptor-related factor-6 (TRAF6), and then further transmits signals. Finally, through phosphorylation, transcription factors such as AP-1, NFKB and IRF3 are activated and enter the nucleus, and then activate interferon-i (IFN- $\alpha$ and IFN- $\beta$ ) and increase the expression of proinflammatory cytokines (IL-1 $\beta$, IL-6, TNF- $\alpha$ ) and chemokines (IL-8). These cytokines play an important role in the pathogenesis of asthma. A lack of TLR activation and Th1 responses during critical periods of immune system maturation may allow Th2 adaptive immunity to predominate. The mutation of TLR genes leads to differences in the function of signal transduction or encoding of proteins, which makes the population carrying the mutation more susceptible to some inflammatory conditions, and the incidence rates, clinical manifestations and therapeutic effects are also affected.

The gene encoding TLR4 in humans is located at the chromosome locus 9q32-q33 and contains four exons. The single nucleotide polymorphism (SNP) rs4986791 consists of a cytosine/thymine substitution at nucleotide 1196 . This SNP causes an amino acid substitution, exchanging an isoleucine for a threonine at position 399. Previous studies have detected an association between this genetic variant and the risk of gall bladder cancer and precancerous gastric lesions, as well as asthma. ${ }^{10-14}$ The relationship between TLR4 SNPs and the severity of asthma and clinical indicators related to asthma have been studied. Zhang et al. and Sackesen et al. found that SNPs in the TLR4 gene may affect the severity of asthma symptoms. ${ }^{15,16}$ Arbour et al. discovered the polymorphism of TLR4 Thr 399 Ile, which confirmed that TLR4 was related to human sensitivity to endotoxin, but the association with asthma was not studied. ${ }^{17}$ For the Thr 399 Ile locus, Füsun Sahin et al. found that there was no significant association between this polymorphism and bronchial asthma. ${ }^{18}$ TLR4 plays an important role in the development of asthma; however, the results of susceptibility studies are inconsistent. ${ }^{19-21}$ To determine whether the variants in TLR4 are associated with bronchial asthma in children, further research is needed.
In this study, the rs4986791 polymorphism of the TLR4 gene was detected in asthmatic children to explore whether the variant is related to the pathogenesis and clinical phenotype of children's asthma.

\section{Materials and Methods Specimens and patients}

In our study, 600 asthmatic patients (aged 3 to $12 \mathrm{y}$ ) were enrolled from January 2017 to September 2019. All subjects were unrelated Han Chinese people residing in HuaiHua City and the surrounding regions in Hunan province in China. The asthmatic patients were consecutively enrolled from the inpatient department at the Huaihua No.1 People's Hospital affiliated to Nanhua University. Asthma diagnosis and severity were verified by an experienced pulmonary specialist according to the Global Initiative for Asthma (GINA) guidelines. ${ }^{22}$ The severity of asthma can be classified as intermittent, mild persistent, moderate persistent and severe persistent according to clinical characteristics. All participants had a history of asthma of at least half a year. Each patient underwent a detailed workup, including medical history, family history, general physical examination, medication, skin prick test (SPT), complete blood count, pulmonary function and extended laboratory tests. All subjects signed informed consent for the study procedures. The study protocol was approved by the institutional ethics committee of the Huaihua No.1 People's Hospital in Hunan province, China.

\section{Determination of SPT and pulmonary function}

The SPT was carried out on the ventral side of the forearm. In total, 25 types of common gas source allergens were used, including house dust mite, dust mite, cat hair, dog hair, cockroach, pollen, ragweed, Artemisia and mold. Histamine was used as a positive control and normal saline as negative control. An average diameter of air mass over $3 \mathrm{~mm}$ was considered to be positive. The pulmonary function was measured using a portable pulmonary function instrument (Microlab Spiro V 1.34, Micro Medical Ltd, UK). The subjects were instructed to perform forced vital capacity measurement, and forced expiratory volume per second (FEV1\%), forced vital capacity per second $(\mathrm{FVC} \%)$ and $\mathrm{FEV}_{1} / \mathrm{FVC}$ were recorded. Measurements were taken three times, recording the best value.

\section{Blood sample collection}

At 7:00-9:00 am, $5 \mathrm{ml}$ of blood was taken from the subjects and collected into vacuum tube containing anticoagulant. Then the blood were transferred into a centrifuge tube, which were centrifuged at $4^{\circ} \mathrm{C}, 1300 \mathrm{~g}$ for $10 \mathrm{~min}$, and the plasma in the upper layer was stored at $-70^{\circ} \mathrm{C}$ for the detection of plasma factors. The other blood cell layer was stored at $-20^{\circ} \mathrm{C}$, which was used to extract genomic DNA.

\section{Determination of plasma IgE and hsCRP}

The level of plasma IgE was measured using the Human IgE ELISA quantitative kit (Huzheng limited company, China), according to the manufacturer's instructions. A method previously described in the literature was used to determine the highly sensitive C-reactive protein (Qian et al.). 


\section{Measurement of isolated DNA}

Genomic DNA was extracted from blood cells using the EZ-10 Spin Column Blood Genomic DNA Minipreps kit (BBI, Shanghai, China). The DNA was quantified using a spectrophotometer (OneDrop OD-1000 nanodrop). Measurements made at 260 and $280 \mathrm{~nm}$ were compared, and DNA samples with a ratio of $\geq 1.6$ were considered to have maximal purity. Then, band intensities were compared with known DNA standards on a $1.5 \%$ agarose gel. The working solution of DNA (approx. $25 \mathrm{ng} / \mu \mathrm{L}$ ) was dissolved in sterile double-distilled water.

\section{Amplification of DNA samples using Bi-PASA}

Two oligonucleotides are used as primers for a reaction series catalyzed by a DNA polymerase. Bi-PASA is a method that uses bi-directional PCR amplification of specific alleles. ${ }^{22}$ The difference between Bi-PASA and standard PCR is that two pairs of primers are used for PCR amplification. The basic principle is to design two primers including the forward and reverse bases at the mutation sites detected by the original PCR. In this way, in the PCR reaction, one allele is amplified by the forward primer and another allele is amplified by the reverse primer. Bi-PASA is a fast, convenient and low-cost SNP detection method, which can detect two alleles of heterotopic sites with only one PCR reaction. For the PCR amplification procedure, template DNA, PCR mix, forward-reverse primer 1, forward-reverse primer 2, and sterile double-distilled water are used. PCR amplifications were performed using a PTC-200 thermal cycler. A total reaction volume of $30 \mu \mathrm{L}$, with $4 \mu \mathrm{L}$ of $10 \times$ buffer, $2.5 \mu \mathrm{L}$ of $25 \mathrm{mmol} \mathrm{MgCl}_{2}$,
$0.4 \mu \mathrm{L}$ of $10 \mathrm{mmol} \mathrm{dNTPs}, 0.2 \mu \mathrm{L}$ of $5 \mathrm{U} / \mu \mathrm{L}$ Taq DNA polymerase, $0.5 \mu \mathrm{L}$ of $10 \mathrm{pmol} / \mu \mathrm{L}$ primers (primer sequences, fragment lengths and genotypes are shown in table 1), and approximately $50 \mathrm{ng}$ of genomic DNA were used. The reaction was carried out by initial denaturation at $94^{\circ} \mathrm{C}$ for $3 \mathrm{~min}$, and then denaturing at $94^{\circ} \mathrm{C}$ for $45 \mathrm{~s}$, annealing at the temperature optimized for primer pairs for $45 \mathrm{~s}$ and extending at $72^{\circ} \mathrm{C}$ for $45 \mathrm{~s}$ for 35 cycles, followed by an extra extension step at $72^{\circ} \mathrm{C}$ for $5 \mathrm{~min}$. PCR products were subjected to electrophoresis on a $2 \%$ agarose gel and evaluated using a Gel Imaging System (Tianneng, Shanghai, China).

\section{Statistical analysis}

Allele frequency tests using the Hardy Weinberg equilibrium with goodness of fit were performed using a chi square test $\left(\chi^{2}\right)$. Statistical analyses were performed using SAS Statistics 9.1.3 software (SAS Institute, Cary, NC, USA). $P$ values under 0.05 were considered significant.

\section{Results}

\section{Demographic characteristics}

Demographic characteristics of the 600 bronchial asthmatic patients are shown in table 2 .

\section{Distribution of alleles}

The Bi-PASA amplification product of TLR4 is $1023 \mathrm{bp}$; however, when the TLR4 $1196 \mathrm{C}-\mathrm{T}$ base exchange is present, the product is $1023+570+453 \mathrm{bp}$ (Figure 1), and when the TLR4 1196 C-C base change is present, the product is $1023+$ 453 bp (Figure 1).

Table 1. The primer sequences, fragments length and genotypes were shew.

\begin{tabular}{|c|c|c|}
\hline Genotypes & Primer sequences & $\begin{array}{l}\text { Fragment } \\
\text { length }\end{array}$ \\
\hline \multirow{4}{*}{$\begin{array}{l}\text { TT } \\
1023 b p+570 b p\end{array}$} & F1:5'-GACCTGTCCCTGAACCCT-3' & \multirow{2}{*}{$1023 \mathrm{bp}$} \\
\hline & R1:5'-ACAAGAACCTGGAGGGAGT-3' & \\
\hline & F2: 5'-ggggcgggcgGTTCTCAAAGTGATTTTGGGACAAT-3' & \multirow{2}{*}{$570 \mathrm{bp}$} \\
\hline & R1:5'-ACAAGAACCTGGAGGGAGT-3' & \\
\hline \multirow{6}{*}{$\begin{array}{l}\text { CT } \\
1023 b p+570 b p+453 b p\end{array}$} & F1:5'-GACCTGTCCCTGAACCCT-3' & \multirow{2}{*}{$1023 \mathrm{bp}$} \\
\hline & R1:5'-ACAAGAACCTGGAGGGAGT-3' & \\
\hline & F2:5'-ggggcgggcgGTTCTCAAAGTGATTTTGGGACAAT-3' & \multirow{2}{*}{$570 \mathrm{bp}$} \\
\hline & R1:5'-ACAAGAACCTGGAGGGAGT-3' & \\
\hline & F1:5'-GACCTGTCCCTGAACCCT-3' & \multirow{2}{*}{$453 \mathrm{bp}$} \\
\hline & R2:5'-ggggcgggcgCTCAGATCTAAATACTTTAGGCTGG-3' & \\
\hline \multirow{2}{*}{$\begin{array}{l}\text { CC } \\
1023 b p+453 b p\end{array}$} & F1:5'-GACCTGTCCCTGAACCCT-3' & \multirow{2}{*}{$1023 \mathrm{bp}$} \\
\hline & R1:5'-ACAAGAACCTGGAGGGAGT-3' & \\
\hline
\end{tabular}


Table 2. Demographic characteristics of subjects.

\begin{tabular}{|lc|}
\hline \multicolumn{1}{|c}{ Subjects } & Parameter values (Mean \pm SD) \\
\hline Age (months) & $45.78 \pm 24.77$ \\
\hline Male (\%) & $369(61.50)$ \\
\hline Female $(\%)$ & $231(38.50)$ \\
\hline Eosinophil $\left(\times 10^{6} / \mathrm{ml}\right)$ & $1.33 \pm 2.15$ \\
\hline FEV1\% $(\%)^{*}$ & $82.63 \pm 9.89$ \\
\hline FEV $/$ FVC $(\%)^{*}$ & $83.05 \pm 11.52$ \\
\hline SPT positive n (\%) & $498(83.00)$ \\
\hline Log ${ }_{10}$ IgE $(\mathrm{IU} / \mathrm{ml})$ & $1.13 \pm 0.73$ \\
\hline HsCRP (mg/L) & $1.96 \pm 5.76$ \\
\hline Severity n (\%) & $188(31.33)$ \\
\hline - Intermittent & $298(49.67)$ \\
\hline - Mild persistent $(\%)$ & $98(16.33)$ \\
\hline - Moderate persistent $(\%)$ & $16(2.67)$ \\
\hline - Severe persistent $(\%)$ & $196(32.67)$ \\
\hline ICS treatment $\mathrm{n}(\%)$ & \\
\hline
\end{tabular}

Abbreviations: FEV1\%, percent of predicted forced expiratory volume in 1 second; $\mathrm{FEV}_{1} / \mathrm{FVC}, \mathrm{FEV}_{1}$ as percentage of forced vital capacity; SPT, skin prick test; ICS, inhaled corticosteroid; IgE, immunoglobulin E levels; SD, standard deviation.

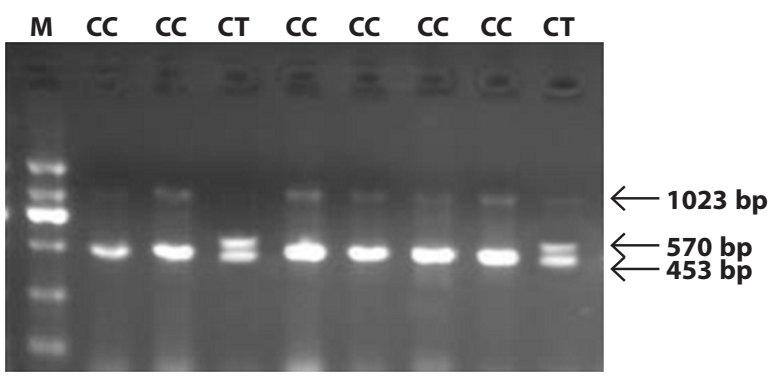

Figure 1. The TLR4 1196C/T gene domain as seen on an agarose gel; CC, $1023+453$ bp; CT, $1023+570+453$ bp (M: marker, $2000 \mathrm{bp}$ ).

Table 3. Distribution of genotypes of the patients and the statistical evaluation.

\begin{tabular}{|c|c|c|c|c|c|c|c|}
\hline \multirow{3}{*}{ Number } & \multicolumn{4}{|c|}{ Genotype frequency } & \multicolumn{2}{|c|}{ Allele frequency } & \multirow{3}{*}{$\begin{array}{c}p \\
\text { values }\end{array}$} \\
\hline & \multicolumn{2}{|c|}{ CT } & \multicolumn{2}{|c|}{$\mathrm{CC}$} & \multirow{2}{*}{$\begin{array}{c}\mathrm{T} \\
\%\end{array}$} & \multirow{2}{*}{$\begin{array}{l}\mathrm{C} \\
\%\end{array}$} & \\
\hline & n & $\%$ & $\mathbf{n}$ & $\%$ & & & \\
\hline 600 & 382 & 63.67 & 218 & 36.33 & 31.83 & 68.17 & $<0.01$ \\
\hline
\end{tabular}

According to the bi-directional PCR amplification results, we found that there were two genotypes at rs4986791 of the TLR4 gene, namely the CC and CT genotypes. The genotype frequency, allele frequency and statistical evaluation are presented in table 3. According to the Hardy Weinberg equilibrium coincidence test, there is a significant difference $(p<$ 0.01 ), indicating that the sample did not conform to the Hardy Weinberg equilibrium law.

\section{Relationship between genotypes and asthma-related clinical indicators}

There was no association between the $1196 \mathrm{C} / \mathrm{T}$ genotype of TLR4 and hemoglobin level, proportion of neutrophils or lymphocytes, leukocyte, basophil or eosinophil counts, lo$\mathrm{g}_{10}$ IgE or hsCRP in the peripheral blood of bronchial asthmatic patients. However, the eosinophil ratio, FEV1\% and $\mathrm{FEV}_{1} /$ FVC level of asthma patients with the CT genotype were lower than those of patients with the CC genotype, which were $1.19 \pm 0.10$ and $1.67 \pm 0.18(P=0.01), 81.25 \pm 0.50$ and 84.99 $\pm 0.65(P<0.0001)$, and $81.72 \pm 0.568$ and $5.55 \pm 0.78(P<$ 0.0001 ), respectively (Table 4$)$. The incidence of bronchial asthma in the CT genotype group is higher than that in the CC genotype group. An influence analysis between the two genotypes and the current medical history of bronchial asthma was conducted using multiple logistic regression $(P$ $<0.05)$. Patients with moderately persistent asthma with the CT genotype are more likely to progress to severely persistent asthma than patients with the CC genotype $(P<0.01)$.

Table 4. Association of TLR4 polymorphisms with asthma-related phenotypes.

\begin{tabular}{|c|c|c|c|}
\hline \multirow{2}{*}{ Subject } & \multicolumn{2}{|c|}{ Genotype } & \multirow{2}{*}{$p$ values } \\
\hline & CT & $\mathrm{CC}$ & \\
\hline Hemoglobin $(\mathrm{mg} / \mathrm{ml})$ & $107.6 \pm 0.78$ & $107.2 \pm 1.22$ & 0.77 \\
\hline Leukocyte count $\left(\times 10^{6} / \mathrm{ml}\right)$ & $10.68 \pm 0.26$ & $10.37 \pm 0.52$ & 0.56 \\
\hline Proportion of neutrophils (\%) & $50.34 \pm 1.14$ & $48.90 \pm 1.60$ & 0.45 \\
\hline Lymphocyte proportion (\%) & $40.48 \pm 1.38$ & $40.56 \pm 1.42$ & 0.97 \\
\hline Basophil count $\left(\times 10^{6} / \mathrm{ml}\right)$ & $0.03 \pm 0.002$ & $0.14 \pm 0.11$ & 0.18 \\
\hline Eosinophil count $\left(\times 10^{6} / \mathrm{ml}\right)$ & $0.13 \pm 0.01$ & $0.45 \pm 0.26$ & 0.11 \\
\hline Basophil ratio (\%) & $0.263 \pm 0.01$ & $0.28 \pm 0.01$ & 0.38 \\
\hline Eosinophil ratio (\%) & $1.19 \pm 0.10$ & $1.67 \pm 0.18$ & 0.01 \\
\hline FEV1\% (\%) & $81.25 \pm 0.50$ & $84.99 \pm 0.65$ & $<0.0001$ \\
\hline $\mathrm{FEV}_{1} / \mathrm{FVC}(\%)$ & $81.72 \pm 0.56$ & $85.55 \pm 0.78$ & $<0.0001$ \\
\hline $\log _{10} \operatorname{IgE}(\mathrm{IU} / \mathrm{ml})$ & $1.17 \pm 0.51$ & $1.08 \pm 0.72$ & 0.56 \\
\hline $\mathrm{HsCRP}(\mathrm{mg} / \mathrm{L})$ & $1.97 \pm 5.87$ & $1.94 \pm 4.64$ & 0.37 \\
\hline Intermittent n (\%) & $128(21.33)$ & $60(10.00)$ & $<0.01$ \\
\hline Mild ersistent n (\%) & $187(31.17)$ & $111(18.50)$ & $<0.0001$ \\
\hline Moderate persistent n (\%) & $59(9.84)$ & $39(6.50)$ & $P<0.05$ \\
\hline Severe persistent n (\%) & $8(1.30)$ & $8(1.30)$ & $>0.05$ \\
\hline
\end{tabular}




\section{Discussion}

Asthma is a common respiratory disease, but its pathogenesis is still unclear at present. Many researchers believe that the development of this disease is based on genetic factors that influence susceptibility. Therefore, much research on the relationship between TLR gene polymorphisms and asthma has been conducted in recent years, which has been important in efforts to clarify the genetic basis and susceptibility of this disease. Results from research into TLR gene polymorphisms and experimental work relating to asthma are constantly being reported. However, the results of different studies may differ due to many factors, such as region, race and case collection. TLR4 is the main receptor used by the immune system to recognize pathogenic microorganisms, playing an important role in the innate immune response. At the same time, TLR4 can promote the generation of acquired immunity, which is the key to connecting innate immunity and acquired immunity. The human TLR4 gene is located at 9q32-9q33, and more than 200 polymorphic loci have been found and included in the NCBI database. At present, it is believed that the Thr 399 Ile and Asp 299 Gly alleles are closely related to the inflammatory response. These are missense mutations, isoleucine is changed to threonine due to a cytosine to thymine mutation at position 1196 of TLR4, and after the mutation of adenine to guanine, aspartic acid at position 299 of TLR4 is changed to glycine.

From the comparative analysis of results from Chinese and Euramerican individuals, the incidence of the Asp 299 Gly mutant in the TLR4 gene is relatively low in the Chinese population. In many studies, no mutations were detected at this locus in TLR4. However, the Asp 299 Gly mutation is more common in European and American people. For this reason, the polymorphism at position 896 of the TLR4 was not studied in this experiment. In this study, only CT and CC genotypes were found, while the TT genotype was not detected. This result was similar to the results of Shu et al. Concerning the rs4986791 polymorphism of the TLR4 gene in Hubei people in China, the TT genotype has not been detected..$^{23}$ The incidence of bronchial asthma in people with the CT genotype is higher than that in people with the CC genotype. A comparative analysis between the two genotypes and bronchial asthma in children has been performed. Patients with moderately persistent asthma who have the CT genotype are more likely to progress to severely persistent disease than those with the CC genotype. This conclusion is similar to the results of many previous studies. ${ }^{24-33}$ TLR4 plays an important role in the development of asthma. It is well known that the main immunological feature of asthma is an imbalance of Th1/Th2 leading to an excessive Th2 response. TLR4 plays an important role in host defense by activating host innate immunity and acquired immunity against bacterial infection, but inappropriate TLR4 responses can lead to acute and chronic inflammatory responses. ${ }^{34}$ TLR4 is activated after binding with LPS. Through phosphorylation and dephosphorylation of a series of downstream adaptor molecules, it activates NF- $\mathrm{KB}$, which finally leads to the expression and production of inflammatory factors and regulatory factors such as interferon (IFN)- $\alpha$, tumor necrosis factor (TNF)- $\alpha$, interleukin (IL)- $1 \beta$,
IL-6, and IL-12. This induces antigen-presenting cell (APC) maturation and promotes Th 0 cell differentiation to Th $1 .{ }^{35}$

In this study, TLR4 SNPs were found to affect lung function (the eosinophil ratio, FEV1\% and $\mathrm{FEV}_{1} / \mathrm{FVC}$ level) and severity of asthma, which was consistent with a previous report by Sackesen et al. ${ }^{28}$ It has been reported that activation of TLR4 can directly or indirectly affect the function of regulatory $\mathrm{T}$ cells, thus affecting the Th1/Th2 balance. TLR4 is highly expressed on the surface of $\mathrm{CD} 4^{+} \mathrm{CD} 25^{\text {high }}$ regulatory $\mathrm{T}$ cells, which play an important role in the development of asthma. However, the role of TLR4 has not been studied. The mechanism of asthma is complex; whether the TLR4 Thr 399 Ile mutation is causal or not needs to be studied, as this may be of value in uncovering the pathogenesis of and developing immunotherapies for bronchial asthma.

The result of this study may be helpful in adding to the information regarding the potential functional changes due to this SNP. However, there is still much work to be done in investigating the pathogenesis, treatment and prevention of asthma. This may include searching for the susceptibility-associated genes in different populations, carrying out corresponding gene therapy and looking for immunotherapy strategies. Investigating whether changes amino acids indicate that a particular SNP has functional consequences or whether it is closely related to other functional changes may be the main research direction for asthma treatment in the future. On the other hand, the role of other factors such as neuromodulation and environmental impact in the pathogenesis of asthma and the relationship between them are worthy of further study.

\section{Conclusion}

TLR4 SNPs are not associated with hemoglobin levels, the proportion of neutrophils or lymphocytes, leukocyte, basophil or eosinophil counts, $\log _{10}$ IgE or hsCRP in the peripheral blood of asthmatic patients, but the eosinophil ratio, FEV1\% and $\mathrm{FEV}_{1} / \mathrm{FVC}$ level of asthma patients with the CT genotype was lower than those of patients with the CC genotype. The incidence of bronchial asthma in patients with the CT genotype is higher than that in patients with the CC genotype. We conducted an analysis of the influence between the two genotypes and the current medical history of bronchial asthma of the patients by multiple logistic regression. Patients with moderately persistent asthma with the CT genotype are more likely to progress to severely persistent disease than those with CC genotype. This suggests that the TLR4 gene is associated with asthma, which provides a theoretical basis for gene therapy to treat asthma in Chinese children.

\section{Acknowledgements}

The authors would like to acknowledge the reviewers for their helpful comments on this paper, and thank Dr. Lin Wei for his support and guidance on the experimental and writing process. This work was supported by the Research Foundation of the Department of Health of Hunan Province, grant number B2017180. 


\section{Conflicts of interest}

The authors declare no conflicts of interest.

\section{References}

1. Ambrosino N, Paggiaro P. The management of asthma and chronic obstructive pulmonary disease: current status and future perspectives. Expert Rev Respir Med. 2012;6:117-27.

2. Sun J, Walsh M, Villarino AV, Cervi L, Hunter CA, Choi Y, et al. TLR ligands can activate dendritic cells to provide a MyD88-dependent negative signal for Th2 cell development. J Immunol. 2005;174(2):742-51.

3. Ribatti D, Puxeddu I, Crivellato E, Nico B, Vacca A, Levi-Schaffer F. Angiogenesis in asthma. Clin Exp Allergy. 2009;39:1815-21.

4. Ober C, Hoffjan S. Asthma genetics 2006: the long and winding road to gene discovery. Genes Immun. 2006;7:95-100.

5. Ferreira MA, Matheson MC, Duffy DL, Marks GB, Hui J, Le Souëf P, et al. Identification of IL6R and chromosome $11 \mathrm{q} 13.5$ as risk loci for asthma. Lancet. 2011;378(9795):1006-14.

6. Takeda K, Kaisho T, Akira S. Toll-like receptors. Annu Rev Immunol. 2003;21:335-76

7. Iwasaki A, Medzhitov R. Regulation of adaptive immunity by the innate immune system. Science. 2010;327(5963):291-5.

8. Barton GM, Medzhitov R. Toll-like receptor signaling pathways. Science. 2003;300(5625):1524-35.

9. Conroy H, Marshall NA, Mills KH. TLR ligand suppression or enhancement of Treg cells? A double-edged sword in immunity to tumours. Oncogene. 2008;27(2):168-80.

10. Raby BA, Klimecki WT, Laprise CR, Yannick F, Janet L, Mathieu G, et al. Polymorphisms in toll-like receptor 4 are not associated with asthma or atopy-related phenotypes. Am J Respir Crit Care Med. 2002;166:1449-56.

11. Eder W, Klimecki W, Yu L Z, Von M E, Riedler J, Braun C, et al. Toll-like receptor 2 as a major gene for asthma in children of European farmers. J Allergy Clin Immunol. 2004;113:482-8.

12. Fagerås Böttcher M, Hmani-Aifa $\mathrm{M}$, Lindström A, Christina JM, Mai, $\mathrm{XM}$, Lennart N, et al. A TLR4 polymorphism is associated with asthma and reduced lipopolysaccharide induced interleukin-12 (p70) responses in Swedish children. J Allergy Clin Immunol. 2004;114:561-7.

13. Yang I, Barton S, Rorke S, et al. Toll-like receptor 4 polymorphism and severity of atopy in asthmatics. Genes Immun. 2004;5:41-5.

14. Kormann M,Depner M, Hartl D, Klopp N, Illig, T, Adamski, J, et al. Toll-likereceptor heterodimer variants protect from childhood asthma. J Allergy Clin Immunol. 2008;122:86-92.

15. Zhang Q, Qian FH, Zhou LF, Wei GZ, Jin GF, Bai JL, et al. Polymorphisms in toll-like receptor 4 gene are associated with asthma severity but not susceptibility in a Chinese Han population. J Investig Allergol Clin Immunol. 2011;21:370-7.

16. Sackesen C, Karaaslan C, Keskin O, Tokol N, Tahan F, Civelek E, et al. The effect of polymorphisms at the CD14 promoter and the TLR4 gene on asthma phenotypes in Turkish children with asthma. Allergy. 2005;60:1485-92.

17. Arbour NC, Lorenz E, Schutte BC, Zabner J, Kline JN, Jones M, et al. TLR4 mutations are associated with endotoxin hyporesponsiveness in humans. Nat Genet. 2000;25:187-91

18. Sahin F, Yildız P, Kuskucu A, Kuskucu MA, Karaca N, Midilli K. The effect of CD14 and TLR4 gene polymorphisms on asthma phenotypes in adult Turkish asthma patients: a genetic study. BMC Pulm Med. $2014 ; 14: 20-8$
19. Hsieh YY, Wan L, Chang CC, Tsai $\mathrm{CH}$, Tsai FJ. STAT $2^{*} \mathrm{C}$ related genotypes and allele but not TLR4 and CD40 gene polymorphisms are associated with higher susceptibility for asthma. Int J Biol Sci. 2009;5: 74-81.

20. Reijmerink NE, Bottema RWB, Kerkhof M, Gerritsen J, Stelma FF, Thijs $\mathrm{C}$, et al. TLR-related pathway analysis: novel gene-gene interactions in the development of asthma and atopy. Allergy. 2010;65:199-207.

21. Lachheb J, Dhifallah IB, Chelbi H, Hamzaoui K, Hamzaoui A. Toll-like receptors and CD14 genes polymorphisms and susceptibility to asthma in Tunisian children. Tissue Antigens. 2008;71:417-25.

22. Global Initiative for Asthma. Global strategy for asthma management and prevention [Internet]. Fontana; c2020 [cited 2020 Jun 15]. Available from: http://www.ginasthma.org.

23. Shu Y, Zhang PA, Tong YQ. Research of rs4986790 and rs4986791 single nucleotide polymorphisms in TLR4 and susceptibility of helicobacter pyloriinfection. Lab Med Clin. 2015;12:295-7.

24. Zhao JL, Shang HH, Cao XP, Huang YL, Fang XY, Zhang SD, et al Association of polymorphisms in TLR2 and TLR4 with asthma risk. Medicine. 2017;96:35(e7909).

25. Voron'ko OE, Dmitrieva-Zdorova EV, Latysheva EA, Aksenova MG Archakov AI. CARD15 and TLR4 genes polymorphisms in atopic bronchial asthma. Mol Biol (Mosk). 2011;45:831-9.

26. Liu RM, Wu JM, Cui T, Li Y. Asp299Gly and Thr399Ile polymorphisms in the tol-1 like receptor 4 and the susceptivity of allergic asthma. Chin J Microbiol Immunol. 2005;25:94-7.

27. Bahrami H, Daneshmandi S, Heidarnazhad H, Pourfathollah AA. Lack of association between toll like receptor- 2 and toll like receptor- 4 gene polymorphisms and other feature in Iranian asthmatics patients. Iran J Allergy Asthma Immunol. 2015;14:48-54.

28. Saçkesen C, Karaaslan C, Keskin O, Tokol N, Tahan F, Civelek E, et al The effect of polymorphisms at the CD14 promoter and the TLR4 gene on asthma phenotypes in Turkish children with asthma. Allergy. 2005;60: 1485-92.

29. Sinha S, Singh J, Jindal SK. Role of TLR4 C>1196T (Thr399Ile) and TLR4 A>896G (Asp299Gly) polymorphisms in a North Indian population with asthma: a case-control study. Int J Immunogenet. 2014;41:463-71.

30. Saçkesen C, Karaaslan C, Keskin O, Tokol N, Tahan F, Civelek E, et al. The effect of polymorphisms at the CD14 promoter and the TLR4 gene on asthma phenotypes in Turkish children with asthma. Allergy. 2005;60(12): 1485-92.

31. Kleeberger SR, Reddy S, Zhang, LY, Jedlicka, AE. Genetic susceptibility to ozone-induced lung hyperpermeability: Role of Toll-like receptor 4 . Am J Respir Cell Mol Biol. 2000;22(5):620-7.

32. Garantziotis S, Li ZW, Potts EN, Lindsey JY, Hollingsworth JW. TLR4 is necessary for hyaluronan-mediated airway hyperresponsiveness after ozone inhalation. Am J Respir Crit Care Med. 2010;181(7):666-75.

33. Khatri SB, Fernando, C, Holguin, P, Barry, Ryan, David, et al. Association of ambient ozone exposure with airway inflammation and allergy in adults with asthma. J Asthma. 2009;46(8):777-85.

34. Kawai T, Akira S. The role of pattern-recognition receptors in innate immunity: update on Toll-like receptors.Nat Immunol. 2010;11(5):373-84.

35. Akira S, Takeda K. Toll-like receptor signaling. Nat Rev Immunol. 2004; 4(7):499-511. 